\title{
Are Psychotropic Medications Effective in Chronic Pain Management in Children and Adolescents? A Meta-Analysis of Randomized Control Trials
}

\author{
Taranjeet Jolly' \\ Zeeshan Mansuri $^{2}$ \\ Chintan Trivedi ${ }^{3}$ \\ Mahwish Adnan ${ }^{4}$ \\ Steven P Cohen ${ }^{5}$ \\ To-Nhu $\mathrm{Vu}^{6}$
}

'Department of Psychiatry \& Behavioral Health, Penn State University College of Medicine, Inpatient Child and Adolescent Psychiatry, Pennsylvania Psychiatric Institute, Harrisburg, PA, USA; ${ }^{2}$ Department of Psychiatry, Boston Children's Hospital/Harvard Medical School, Boston, MA, USA; ${ }^{3}$ Psychiatry Department, St. David's Medical Center, Austin, TX, USA; ${ }^{4}$ Department of Psychiatry, Mercy Hospital and Medical Center, Lincolnwood, IL, USA;

${ }^{5}$ Department of Anesthesiology \& Critical Care medicine, Neurology and Physical Medicine \& Rehabilitation, Johns Hopkins School of Medicine, Baltimore, MD, USA; ${ }^{6}$ Department of Anesthesia \& Pain Medicine, Penn State University College of Medicine, Hershey, PA, USA
Correspondence: Taranjeet Jolly Department of Psychiatry \& Behavioral Health, Penn State College of Medicine, Inpatient Child and Adolescent Psychiatry, Pennsylvania Psychiatric Institute, 250I N 3rd Street, Harrisburg, PA, USA Tel +l 734-837-6549

Email tjolly@pennstatehealth.psu.edu
Objective: Data defining and subsequently guiding the use of psychotropic medications in children and adolescents is sparse. We conducted a meta-analysis of randomized control trials to examine the effectiveness of psychotropic medications in children and adolescents with chronic pain.

Methods: We conducted a comprehensive literature search from published studies, and annual scientific sessions of psychiatry conferences. We identified double-blind, randomized control trials (RCTs) in which psychotropic medications were compared to placebo. Data was collected for the total number of patients, baseline characteristics, and changes in pain score. Meta-analysis was performed using a random effect model evaluating average change in pain score and the number of patients with a reduction in pain score for both groups. Pooled data are expressed as standardized mean differences (SMD) and odds ratios (OR) with 95\% confidence intervals (CI).

Results: We found 5 studies that included amitriptyline $(n=2)$, citalopram $(n=1)$, buspirone $(n=1)$ and duloxetine $(n=1)$. In the pooled analysis for the difference in the average change in pain score, 4 RCTs with 395 patients were included. After 12-13 weeks of therapy, reductions in pain score were significantly greater in the psychotropic drug group as compared to placebo (SMD: $-0.77,95 \% \mathrm{CI}-1.54,0.0001, \mathrm{p}=0.05$ ). For the analysis on the number of patients with a reduction in pain, data were available for 445 patients (224-medication group, 221-placebo group). More patients in the psychotropic drug group experienced a meaningful reduction in pain score at 12-13 weeks of therapy compared to placebo (OR 1.66, 95\% CI 1.08-2.54, $\mathrm{p}=0.02$ ).

Conclusion: The results of this meta-analysis demonstrate significant analgesic efficacy of psychotropic medications in the management of children with chronic pain. This review is limited by the small number of studies included for analysis. There is a pressing need for more robust clinical trials to further investigate these promising findings.

Keywords: chronic pediatric pain, psychotropic, anti-depressants, anti-anxiety medications, meta-analysis

\section{Introduction}

Pediatric chronic pain is a notable health problem with a prevalence rate of $20 \%$ to $35 \%$ in children and adolescents. ${ }^{1,2}$ Pediatric pain is not only common but also underrecognized and, consequently, under-treated. Overall, more than $10 \%$ of all hospitalized children experience chronic pain. ${ }^{3}$ Data indicate that female patients report more pain than male patients, and the incidence peaks at an average age of 14 years. ${ }^{4}$ Perquin et al 2000 described headache as the most common pediatric complaint at $23 \%$, followed by 
abdominal pain (22\%) and limb pain (22\%). Older children report pain more frequently than younger children. $8 \%$ of school-aged children reported chronic pain. ${ }^{4}$ Chronic pain affects multiple aspects of the patient and their family's lives. ${ }^{5}$ In a more recent study, Roth-Isigkeit et al 2004 reported that $3.5 \%$ of children experience daily pain. ${ }^{6}$

A large proportion of children and adolescents report disability and distress associated with chronic pain. They also describe limitations with participation in daily activities of childhood, including school, play, and sleep. ${ }^{6,7}$ Anxiety frequently accompanies chronic pain. ${ }^{8} \mathrm{~A}$ characteristic pattern of disability associated with chronic pain includes co-morbid depression and maladaptive coping, which are more notable in younger age groups. ${ }^{9,10}$ Family dynamics and functioning are often adversely affected when children are dealing with chronic pain issues, ${ }^{11,12}$ with parents and siblings reporting significant distress. Jordan et al 2007 found that these parents experience high levels of anxiety and depression, which in turn may create a vicious circle resulting in early onset depression in children. ${ }^{11}$ A cost-of-illness study in the United Kingdom found the overall annual cost to a household containing a child living with idiopathic chronic pain was three times higher than the average cost of living for a family. ${ }^{13}$

Chronic pain in children can be managed with both pharmacological and non-pharmacological strategies. Pharmacologically, pediatric chronic pain is typically treated with medications such as NSAIDs, opioids, and psychotropic medications. It is essential to consider the effectiveness and value of pharmacological interventions as stand-alone treatment regimens and as components integrated within a therapeutic approach that better guides care. Preliminary evidence suggests that even for children and adolescents with severe pain and disability, it is possible to reduce the impact of pain on their lives and that on their families. Our objective is to perform a meta-analysis of randomized controlled trials to assess the effectiveness of psychotropic medications in children and adolescents with chronic pain condition.

\section{Materials and Methods \\ Study Outcome}

The primary aim of the study was to evaluate the average pain reduction post-treatment initiation $\mathrm{n}$ in the psychotropic drug group compared to placebo. The secondary aim was to evaluate the treatment response showing meaningful pain reduction or treatment response in psychotropic drug group compared to placebo. Pain scale and definition of meaningful pain reduction or treatment response among the studies are provided in Table 1. Treatment response was defined as 2-point reduction in pain scale ( $\mathrm{n}=2$ studies), $\geq 30 \%$ reduction in pain scale ( $n=1$ study), and for the fourth study good to excellent relief of pain [from failed, poor, fair, good, excellent categories] was defined as treatment response ( $\mathrm{n}=1$ study).

\section{Search Strategy and Study Selection}

Two independent reviewers (C.T. and M.A.) performed a comprehensive literature search from Medline, Google Scholar, PubMed, Cochrane library database, clinicaltrial. gov, and annual scientific sessions of psychiatry conferences for studies published prior to June 2020, with no language or date restrictions. We sought randomized clinical trials that compared psychotropic medications such as antipsychotic, antidepressant, and anxiolytic agents to placebo for chronic pain in children $\leq 18$ years of age. We also performed a search of references of retrieved articles and relevant reviews for further studies. The search strategy keywords were "chronic pain" and/or "children" or "juvenile" or "adolescents," and name of ("individual" or "groups") of psychotropic medications. ${ }^{14}$

\section{Selection of Studies}

Initially, the titles and abstracts of all retrieved studies were examined. Using our search strategy, 226 studies were identified in the initial screening (Figure 1). After excluding review papers, animal experiments, duplicate publications, editorials, and non-randomized clinical trials, we found nine clinical trials. After excluding crossover studies $(n=2)$, those with non-placebo control groups $(\mathrm{n}=1)$, and preventive studies without pain intensity data $(n=1)$, we identified five randomized clinical trials ${ }^{15-19}$ whereby psychotropic agents were compared with placebo for meta-analysis. Four studies assessed antidepressants (amitriptyline $(\mathrm{n}=2)$, citalopram $(\mathrm{n}=1)$, and duloxetine $(\mathrm{n}=1))$, and one evaluated the anxiolytic medication buspirone $(\mathrm{n}=1)$.

\section{Data Extraction}

Data were collected from all studies on baseline characteristics such as age, gender, type of medications, duration of therapy, indications, pain measurement parameters (eg, type of pain scale and anchors), and the total number of patients. For outcome analyses, data were collected on the average change in pain score on a converted 0-to-10 pain scale among the treatment groups. Previous studies have shown a high correlation among pain scales, and conversion to 
Table I Patient and Study Characteristics of Included Studies

\begin{tabular}{|c|c|c|c|c|c|c|c|c|}
\hline & $\begin{array}{l}\text { Age } \\
\text { Group } \\
\text { (Mean } \\
\text { Age) }\end{array}$ & $\begin{array}{c}\text { Female } \\
\mathbf{N}(\%)\end{array}$ & $\begin{array}{c}\text { Number of } \\
\text { Patients } \\
\text { Included in } \\
\text { Psychotropic } \\
\text { Drug Group/ } \\
\text { Placebo }\end{array}$ & $\begin{array}{c}\text { Baseline } \\
\text { Pain Score } \\
\text { (Pain } \\
\text { Scale) }\end{array}$ & $\begin{array}{c}\text { Definition of } \\
\text { Treatment } \\
\text { Response or } \\
\text { Reduction in Pain }\end{array}$ & Indication & Medication & $\begin{array}{c}\text { Follow- } \\
\text { Up } \\
\text { Interval }\end{array}$ \\
\hline $\begin{array}{l}\text { Bahar } \\
\text { et al } \\
2008^{15}\end{array}$ & $\begin{array}{l}12 \text { to } \\
18 \\
(14.7)\end{array}$ & $24(72.7)$ & $16 / 17$ & $\begin{array}{l}6.52 \text { (Visual } \\
\text { analog scale) }\end{array}$ & - & $\begin{array}{l}\text { Irritable Bowel } \\
\text { Syndrome }\end{array}$ & Amitriptyline & $\begin{array}{c}2,6,10,13 \\
\text { weeks }\end{array}$ \\
\hline $\begin{array}{l}\text { Roohafza } \\
\text { et al } \\
2014^{16}\end{array}$ & $\begin{array}{c}6 \text { to } 18 \\
(9.5)\end{array}$ & $56(65.1)$ & $43 / 43$ & $\begin{array}{l}3.70 \text { (Wong- } \\
\text { Baker FACES } \\
\text { Pain Rating } \\
\text { Scale } \\
\text { (WBFPRS) }\end{array}$ & $\begin{array}{l}2 \text { point reduction in } \\
\text { pain scale }\end{array}$ & $\begin{array}{c}\text { Functional } \\
\text { abdominal pain }\end{array}$ & Citalopram & $\begin{array}{l}4,12 \\
\text { weeks }\end{array}$ \\
\hline $\begin{array}{l}\text { Badihian } \\
\text { et al } \\
2020^{17}\end{array}$ & $\begin{array}{c}6 \text { to } 18 \\
(7.8)\end{array}$ & $70(59.8)$ & $59 / 58$ & $\begin{array}{l}3.50 \text { (Wong- } \\
\text { Baker FACES } \\
\text { Pain Rating } \\
\text { Scale } \\
\text { (WBFPRS) }\end{array}$ & $\begin{array}{l}2 \text { point reduction in } \\
\text { pain scale }\end{array}$ & $\begin{array}{c}\text { Functional } \\
\text { abdominal pain }\end{array}$ & Buspirone & $\begin{array}{l}4,12 \\
\text { weeks }\end{array}$ \\
\hline $\begin{array}{l}\text { Upadhyay } \\
\text { et al } \\
2019^{18}\end{array}$ & $\begin{array}{l}13 \text { to } \\
17 \\
(15.5)\end{array}$ & $\begin{array}{c}138 \\
(75.0)\end{array}$ & $91 / 93$ & $\begin{array}{c}5.65 \text { (Brief } \\
\text { Pain } \\
\text { Inventory } \\
\text { short form) }\end{array}$ & $\begin{array}{l}\geq 30 \% \text { reduction in } \\
\text { pain scale }\end{array}$ & $\begin{array}{l}\text { Juvenile } \\
\text { fibromyalgia }\end{array}$ & Duloxetine & 13 week \\
\hline $\begin{array}{l}\text { Saps et al } \\
2009^{19}\end{array}$ & $\begin{array}{l}8 \text { to } 17 \\
(12.7)\end{array}$ & $66(73.3)$ & $46 / 44$ & $\begin{array}{c}47.7 \text { (Visual } \\
\text { analog-Likert } \\
\text { pain scale) }\end{array}$ & $\begin{array}{l}\text { Good to Excellent } \\
\text { relief of pain [from } \\
\text { failed, poor, fair, } \\
\text { good, excellent } \\
\text { categories] }\end{array}$ & $\begin{array}{c}\text { Functional } \\
\text { gastrointestinal } \\
\text { disorders }\end{array}$ & Amitriptyline & 4 weeks \\
\hline
\end{tabular}

a single scale is common in systematic reviews. ${ }^{20}$ In two studies, the pain-score scale (Wong-Baker FACES Pain Rating Scale) scored pain out of six points from 0 to $5 .{ }^{16,17}$ For both of those studies, scores were multiplied by 2 for the final analysis. In one study, score change was provided on a percentage scale wherein the score was divided by 10 for analysis. ${ }^{15}$ In the same study, we averaged the scores of two body areas since separate data was provided for right lower quadrant abdominal pain and periumbilical pain intensity. In addition, dichotomous data on the number of patients with and without a clinically meaningful reduction in pain was collected for treatment and control groups.

\section{Statistical Analysis}

A total of 5 studies were included in the final analysis. Two types of pooled analyses were performed: 1) difference in mean score change between placebo versus drug measured by Hedges' g (standardized mean difference) and 2) proportion of patients with a reduction in pain score. A standardized mean difference (Hedges' g) value of 0.2 , 0.5 , and 0.8 is considered small, moderate, and large, respectively. ${ }^{21}$ In three ${ }^{16-18}$ studies, there were data on preand post-treatment mean pain scores as well the proportion of patients whose pain score was reduced after administration of treatment. In the fourth study, ${ }^{15}$ only data on mean change in pain score was provided, and in the fifth study, ${ }^{19}$ only data on the proportion of patients with a reduction in pain score was provided. Therefore, in both types of pooled analyses, four studies were included. Our primary objective was to assess the treatment effect at 12-13 weeks post-treatment initiation with a secondary analysis performed to evaluate treatment efficacy at 4-6 post-treatment initiation. The pooled analysis for the difference in mean pain score was performed using the DerSimonian and Laird inverse variance method in the random effect model. Summary effects of the proportion of patients with and without a reduction in pain score between 


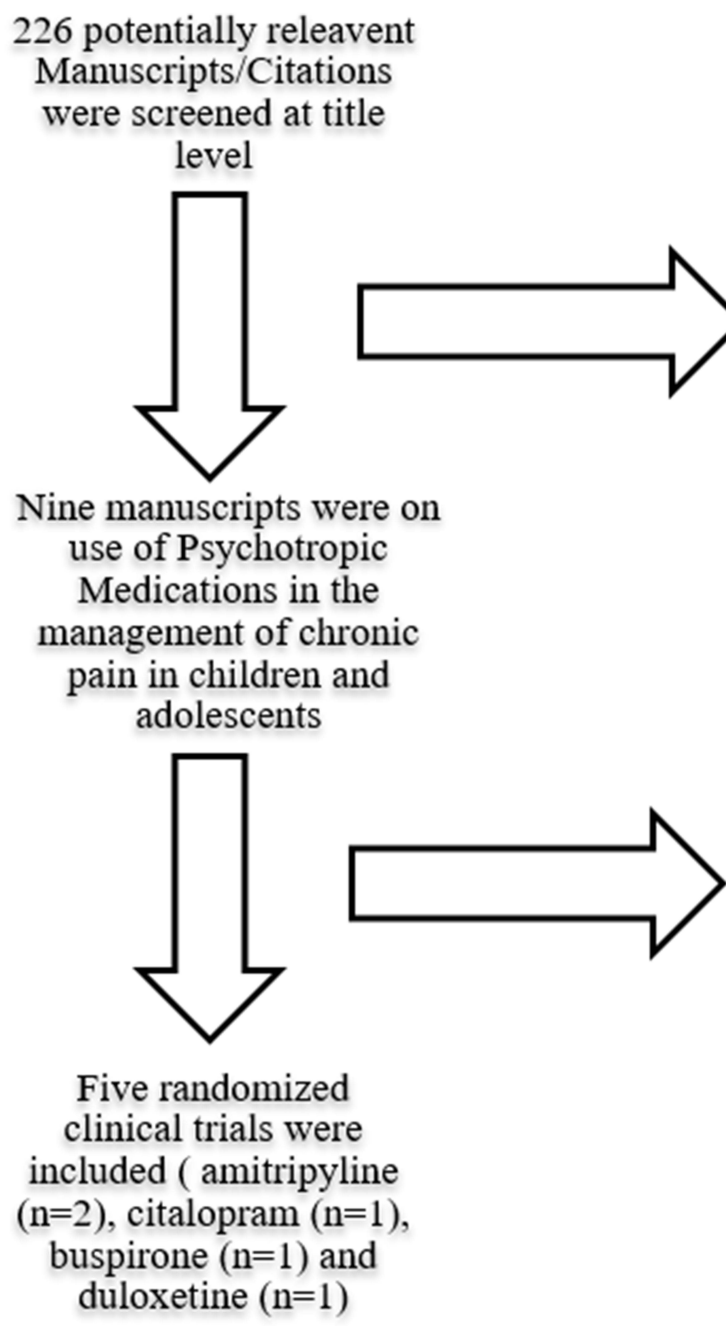
Basic science, review paper, studies in adults, animal model, single group, case reports and study design manuscripts excluded

$$
(\mathrm{n}=217)
$$

\section{Studies Excuded}

[1. Non-placebo comparison (Gabapentin vs. amitriptyline)

2. Study was on frequency of headache episode not on pain intensity

\section{Less than 10 patients and cross over design}

\section{Trial was terminated early because of low enrollment, and had no data ]}

Figure I Selection process of studies included in the systematic review.

the groups were analyzed by the Mantel-Haenszel method in the fixed-effects model. Between-study heterogeneity was assessed using the $X^{2}$ test and measured with the $\mathrm{I}^{2}$ statistic. Significant heterogeneity was considered to be present if $\mathrm{p}<$ 0.05 in the $X^{2}$ test. If significant, further analysis was performed using the Mixed-effects model for meta-regression. Regression coefficients and the associated p-values were reported from the meta-regression analysis. An $\mathrm{R}^{2}$ coefficient was also calculated to indicate the percentage of variance explained by covariates. A bubble plot was used to present the fitted meta-regression model. Publication bias was measured with Begg and Egger tests. Risk of bias among included studies was assessed using the Cochrane risk of bias tool to classify included studies as having low, unclear, or high risk of bias ${ }^{22}$ [Review Manager 5.3]. The risk of bias tool assesses the bias of random sequence generation, allocation concealment, blinding of participants and personnel, blinding of outcome assessment, incomplete outcome data, and selective reporting for each included study. Summary effects were displayed as a forest plot containing a standardized mean difference (SMD) (Hedges' g) for continuous data/odds ratio (OR) for categorical data with $95 \%$ confidence intervals (CI). Data analysis was performed using Metafor with Meta package $e^{23,24}$ implemented in the R Foundation for statistical computing version 3.6.3. ${ }^{25}$

\section{Results}

\section{Study Characteristics}

Baseline patient and study characteristics are shown in Table 1. All studies evaluated individuals with a nociplastic pain condition as recently defined by the International Association for the Study of Pain (IASP). ${ }^{26}$ Unlike nociceptive and neuropathic pain, nociplastic pain is hypothesized to result from central sensitization and is 
not associated with biomarkers or objective evidence of tissue or nerve pathology.

Bahar et al 2008 evaluated amitriptyline efficacy in adolescents with irritable bowel syndrome in a double-blind, placebo-controlled trial. Patients were excluded if they were on any concurrent pharmacotherapy for anxiety, depression, and chronic pain syndrome. In this 13-week study, after two weeks of enrollment, patients received eight weeks of amitriptyline/placebo with three weeks for washout and symptom scoring. The dose of amitriptyline was based on body weight: patients weighing $30-50 \mathrm{~kg}$ received $10 \mathrm{mg}$ OD, 50-80 $\mathrm{kg}$ received $10 \mathrm{mg} \mathrm{BD}$, and $80 \mathrm{~kg}$ or more received $10 \mathrm{mg}$ PO three times a day. The visual analog scale was used to assess pain intensity on a scale of 0 to 10 . Roohafza et al 2014 assessed patients with functional abdominal pain randomized to receive citalopram or placebo for four weeks in a double-blind fashion. Patient pain intensity was measured by Wong-Baker FACES Pain Rating Scale (WBFPRS), where 0 signified "no hurt" and 5 designated "hurt worse." All baseline characteristics were similar between groups except age, which was higher in the citalopram group. Pain was assessed at four and 12 weeks. Citalopram dose was $10 \mathrm{mg}$ for the first week and increased to $20 \mathrm{mg}$ for a total of 4 weeks. Patients taking psychotropic medications in the last two months were excluded. Badihian et al 2020 employed a similar study design to investigate buspirone. The buspirone dose was $2.5-5 \mathrm{mg}$ OD for patients whose age was under 10 years, 5-10 mg per day for ages 10 15 years, and 5-15mg per day for patients $15-18$ years of age. Additionally, Upadhyay et al 2019 evaluated the treatment of juvenile fibromyalgia with duloxetine. Patients were randomized to either duloxetine once a day or placebo in a 13-week study. The dose of duloxetine was 30-60 mg per day, and pain intensity was measured by the 24-hour average pain severity item on the Brief Pain Inventory modified short form. On this scale, 0 signifies no pain and 10 indicates the worst imaginable pain. Patients taking a stimulant, antidepressant, or were previously treated (within six months) with duloxetine were excluded. Lastly, the Saps et al 2009 study was a multicenter randomized placebo-controlled trial of amitriptyline in children with a functional gastrointestinal disorder. In this 4-week study, the amitriptyline dose was $10 \mathrm{mg}$ per day for patients whose weight $\leq 35 \mathrm{~kg}$ and $20 \mathrm{mg} /$ per day for those who weighed more than $35 \mathrm{~kg}$. The pain was assessed on a $0-100 \mathrm{~mm}$ visual analogue scale.

In the risk of bias assessment using the Cochrane Risk of Bias tool (Figure 2), three studies were judged to be at low risk for bias, while the study conducted by Bahar et al 2008, was judged to be at unclear risk, because there was no information on allocation concealment or blinding of outcome assessment. The study from Saps et al 2009 was judged to be at high risk because of reporting bias, as no pain score data were provided at follow-up. In addition, blinding of outcome assessment and allocation concealment was unclear.

\section{Efficacy Outcome}

In the pooled analysis for the difference in pain score between the two groups, 395 (197 in the psychotropic drug group, 198 in the placebo group) patients were included. After 12-13 weeks of therapy, the reduction in pain score was significantly greater in the psychotropic drug group compared to the placebo group with large effect size (SMD (Hedges' g): -0.77 $(-1.54,0.0001)$, p-value: 0.05$)$ (Figure $3 \mathrm{~A})$. There was no publication bias ( $\mathrm{p}$-value: 0.18 ). However, there was significant heterogeneity $\left(\mathrm{I}^{2}: 91 \%\right.$, p-value $\left.<0.001\right)$ among included studies. Consequently, we performed meta-regression to explore the potential effect of covariates (mean age, year of study, baseline pain score, and duration of therapy), which might contribute to heterogeneity. In the meta-regression, we found that only the year of the study was a significant predictor of the summary effect (Beta: 0.23 , p-value $<0.001, \mathrm{R}^{2}: 82.0 \%$ ) (Figure 4). This indicates that there was a lower reduction in pain scores with later studies. The mean age of the participants (p-value: 0.24), baseline pain score (p-value: 0.85), and duration of therapy (p-value: 0.20 ) had no impact on the primary outcome measure. The different medications used in each study and the differences in the pain score measurement scale were potential sources of heterogeneity, although their effects could not be analyzed due to the small number of studies. Further, in a subgroup analysis that included only antidepressants (without buspirone), treatment had better efficacy as indicated by a greater reduction in pain score (SMD: -1.15 (95\% CI: $-2.21,-0.09, \mathrm{p}=0.03)$.

For the subgroup analysis for effect after 4-6 weeks of therapy, there was also a reduction in pain score with large effect size; however, it was not statistically significant (SMD: -0.90 (-2.05, 0.26), p-value: 0.13) (Figure 3B).

In the pooled analysis for the number of patients with a reduction in pain score, 445 (224 in the psychotropic drug group, 221 in the placebo group) patients were included. More patients in the psychotropic drug group experienced a reduction in pain score at 12-13 weeks of therapy compared to placebo (OR: 1.66 (1.08-2.54), p-value: 0.02) (Figure 3C). There was no significant heterogeneity 
A

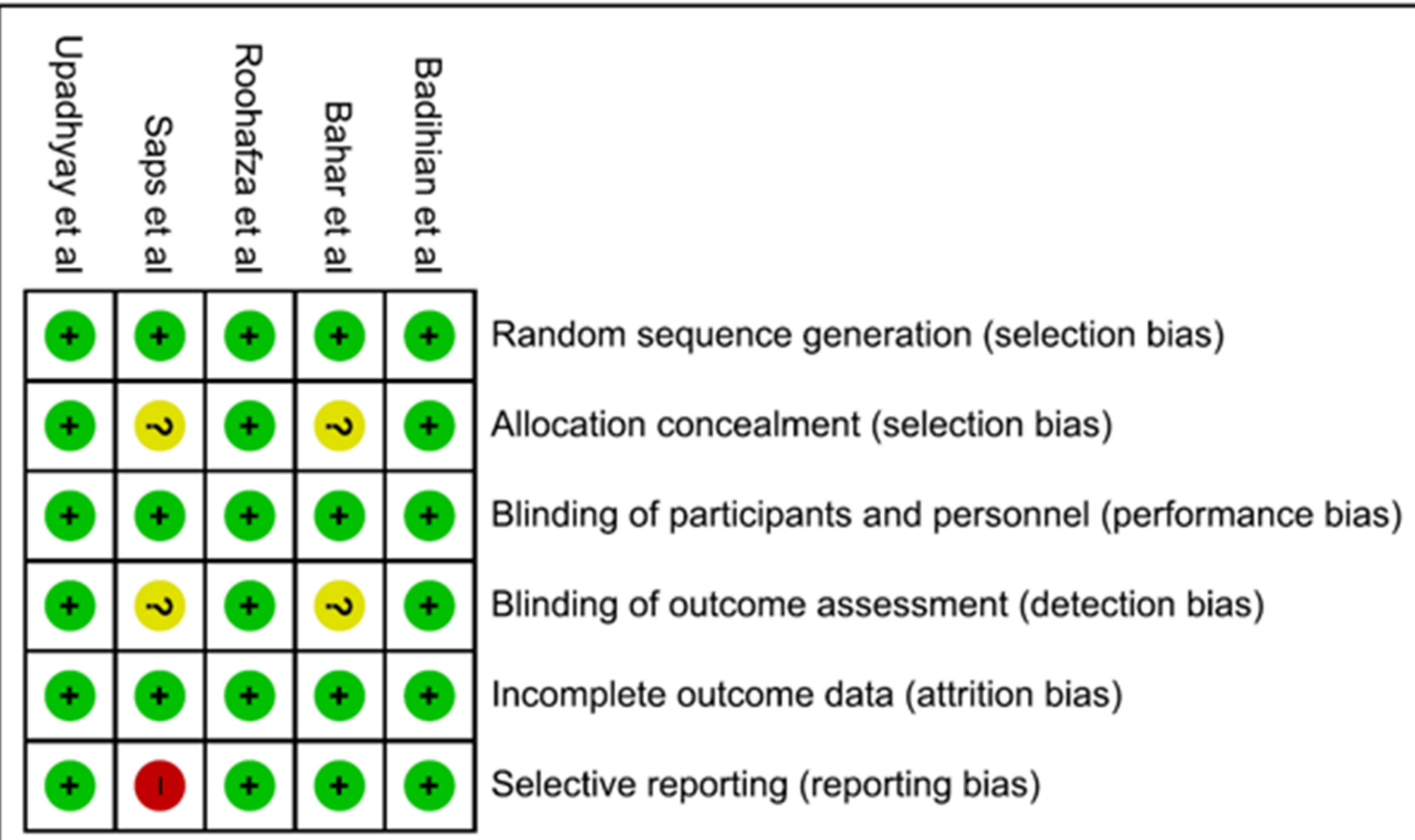

B

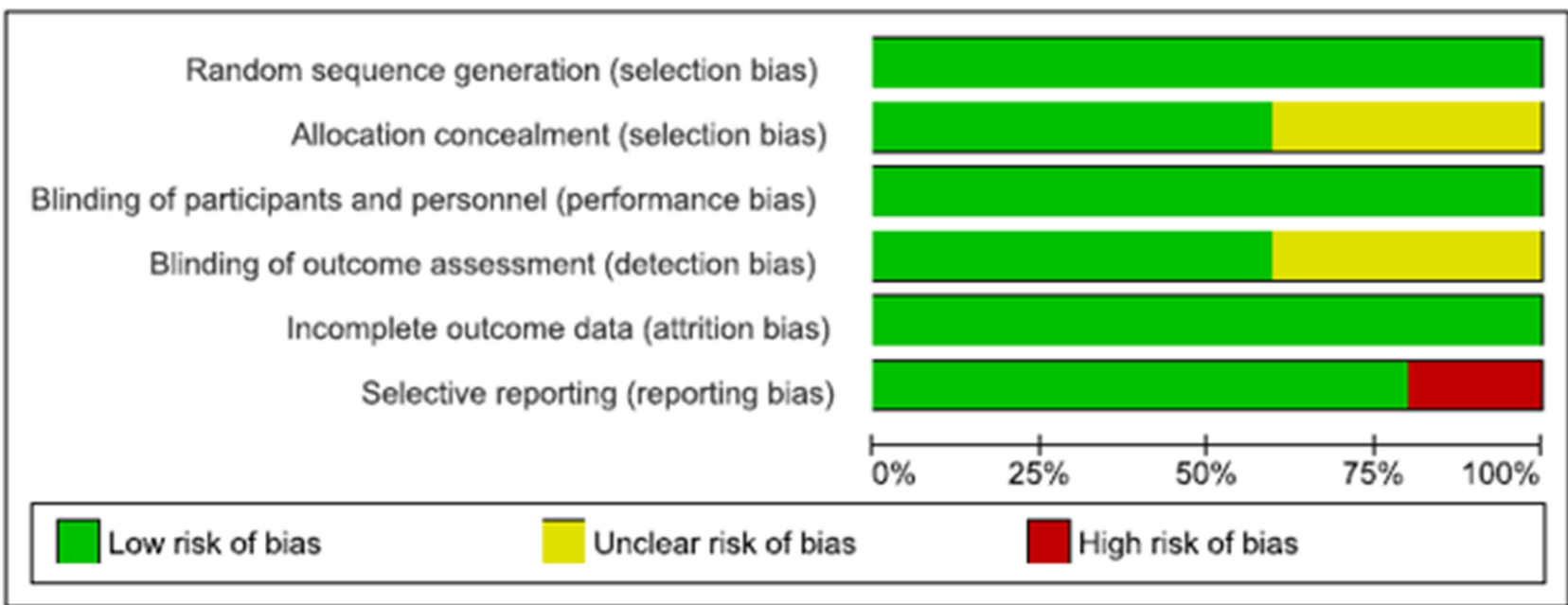

Figure 2 Risk of bias summary: review authors' judgements about each risk of bias item for each included study (A). Risk of bias graph: review authors' judgements about each risk of bias item presented as percentages across all included studies (B).

$\left(\mathrm{I}^{2}: 27.0 \%\right.$, p-value: 0.25$)$ or publication bias (p-value: 0.68$)$ detected. The subgroup analysis containing antidepressants (without buspirone) showed even greater benefits at 12-13 weeks (OR: 2.03, $\mathrm{p}=0.005$ ). For the analysis at four weeks, the number of patients with a reduction in pain score was not statistically significant (OR: 1.28 (0.79-2.08), p-value: 0.32 ). (Figure 3D)

\section{Discussion}

In this meta-analysis, the main findings were: 1) psychotropic medications are effective in children and adolescents with chronic pain conditions and lead to significant reductions of pain intensity compared to placebo at 12-13 weeks of therapy in terms of effect size; 2) almost $66 \%$ more patients in the psychotropic medication group 
A

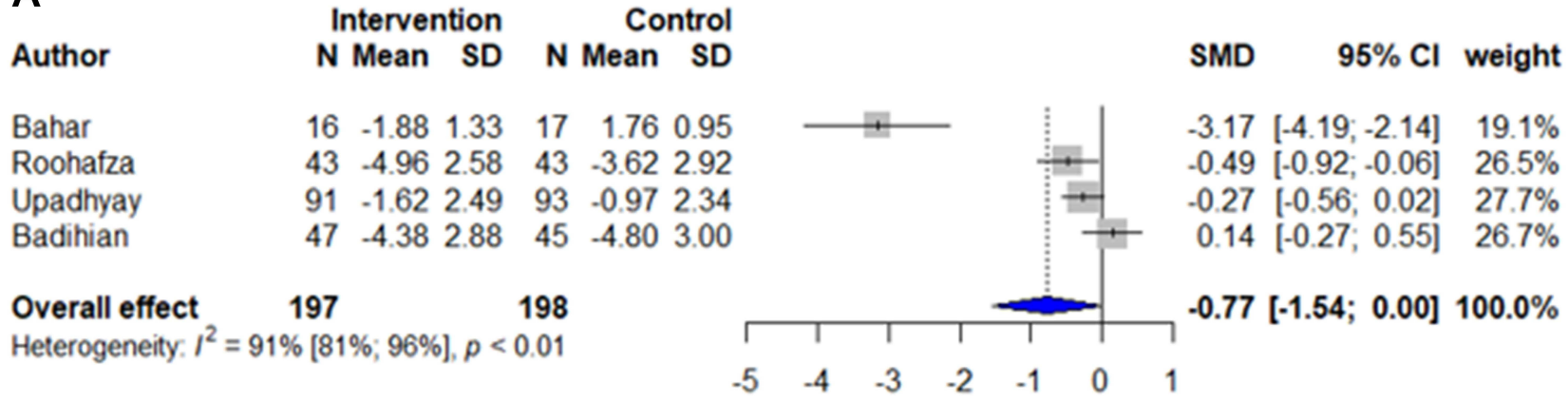

B

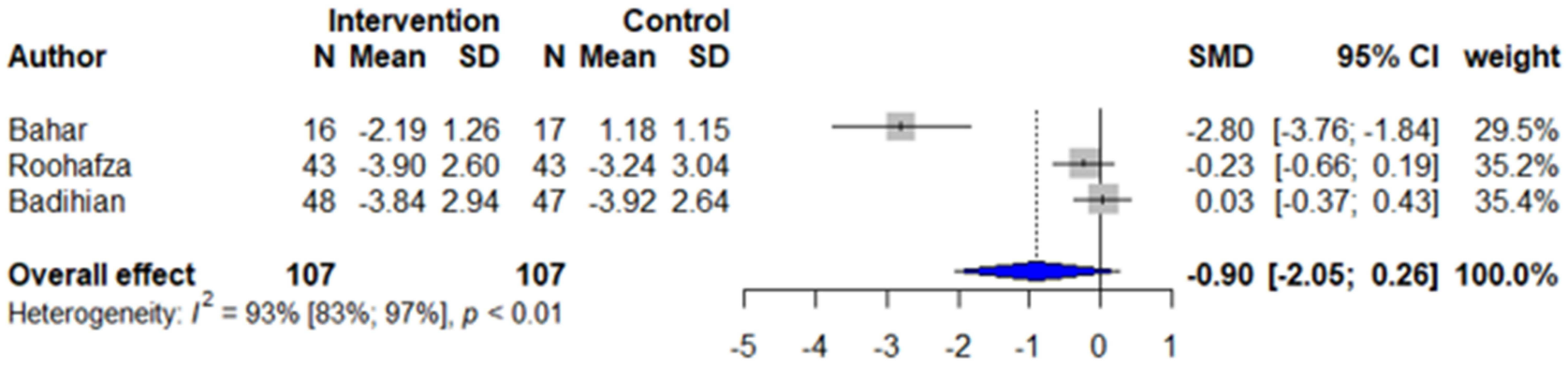

C

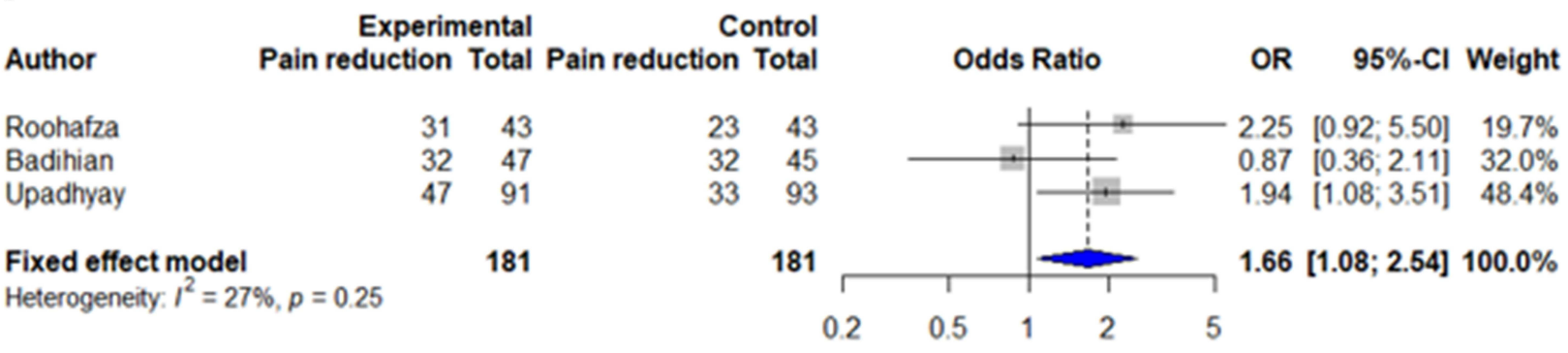

D Author Pain reduction Total Pain reduction Total

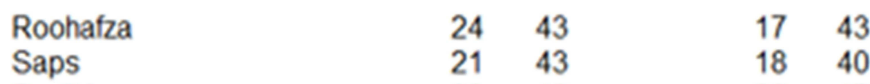

Badihian

$\begin{array}{llll}28 & 48 & 28 & 47\end{array}$

Fixed effect model

134

130

Heterogeneity. $I^{2}=0 \%, p=0.49$

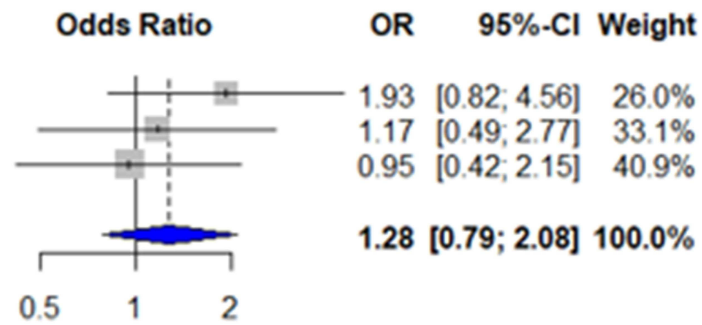

Figure 3 (A) Forest plot showing the Standardized Mean Difference (SMD/Hedges' g) and 95\% confidence interval (Cl) of Change in Pain score after I2-I3 weeks of therapy. (B) Forest plot showing the Standardized Mean Difference (SMD/Hedges' g) and 95\% confidence interval (Cl) of Change in Pain score after 4-6 weeks of therapy. (C) Forest plot showing Odds Ratio (OR) and 95\% confidence interval (Cl) for the number of patients with reduction in pain score after $12-13$ weeks of therapy. (D) Forest plot showing Odds Ratio (OR) and 95\% confidence interval $(\mathrm{Cl})$ for the number of patients with reduction in pain score after 4-6 weeks of therapy. Square boxes denote SMD; horizontal lines represent $95 \%$ confidence interval $(\mathrm{Cl})$. Pooled effects are represented by Diamond.

Abbreviations: $\mathrm{N}$, total patients; OR, odds ratio; SD, standard deviation.

experienced a reduction in pain score compared to placebo; 3) a 4-to-6-week duration of therapy might be too brief to see a meaningful analgesic effect.
To the best of our knowledge, this is the first metaanalysis study to evaluate the effect of psychotropic medications on chronic pain conditions in children and 


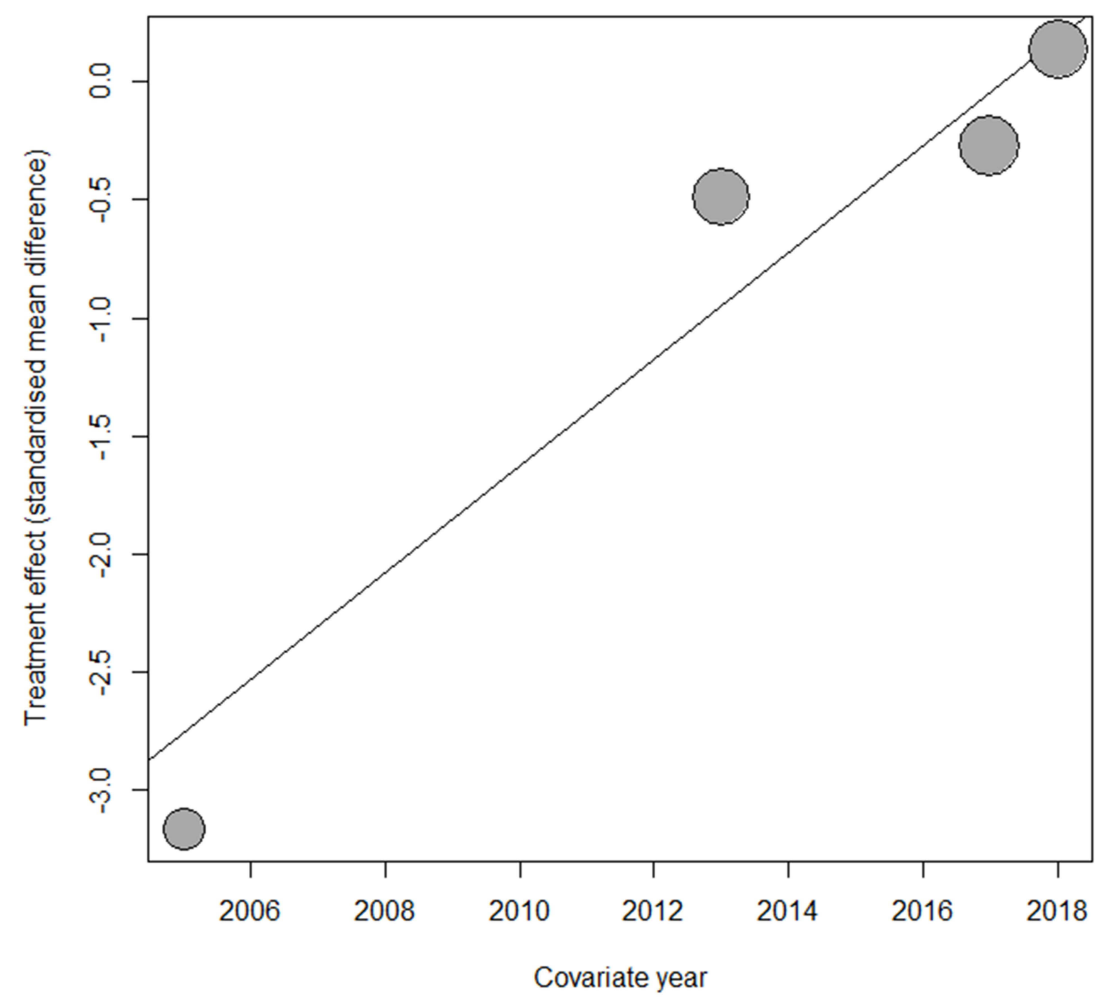

Figure 4 Meta-regression bubble plot of correlation between standardized mean difference of Pain scores and Year of study. Each bubble represents a study and bubble size portrays the study weight. The regression line shows a significant trend for the reduction in the Pain score with increase in year $\left(p<0.00 \mathrm{I}, \mathrm{R}^{2}\right.$ : $82 \%$, Beta: 0.23$)$.

adolescents. In one of the excluded clinical trials, ${ }^{27}$ the authors performed a randomized study comparing amitriptyline to gabapentin in children for complex regional pain syndrome type I, another nociplastic pain condition. They found that amitriptyline demonstrated similar efficacy to gabapentin in the reduction of pain. In a systematic review by Salerno et al 2008 performed in adults with chronic low back pain, the authors concluded that antidepressants effectively reduced the pain severity. ${ }^{28}$ None of the included studies denoted the cause of chronic low back pain, so one may conclude that a high percentage of subjects had non-specific low back pain (very common in children), which many consider to be another nociplastic pain condition.

Several published controlled studies have evaluated amitriptyline, citalopram, duloxetine and other antidepressants in adults, which generally support efficacy in both neuropathic and non-neuropathic pain, with the effect being greater for tricyclic antidepressants and serotoninnorepinephrine reuptake inhibitors than serotonin-specific reuptake inhibitors. ${ }^{29,30}$ For buspirone, although preclinical studies demonstrate antinociceptive effects, ${ }^{31,32}$ the clinical evidence supporting benefit is weak. ${ }^{33}$ In our study, we also observed that without buspirone, pooled effect was greater and more significant. Citalopram has demonstrated some effectiveness in uncontrolled studies, ${ }^{34}$ but the results of controlled studies for both nociplastic pain and other pain conditions are weak, inconsistent, and characterized by methodological shortcomings. ${ }^{35,36}$

The mechanism of action of psychotropic medications in the treatment of chronic pain is still unclear. According to a study by Obata 2017, the inhibitory effect of antidepressants on neuropathic pain occurs more quickly than their effects on mood, which implies that the mechanism of action is not through a change in the mood. According to animal studies, an increase in noradrenaline could be responsible for this action. In addition, serotonin and dopamine may reinforce the noradrenergic effects to inhibit the pain. ${ }^{37}$ Our systematic review was unique in its focus on the analysis of the effect of psychotropic medications in general on chronic pain in children and adolescents, which may be more sensitive to detect statistically small but possess clinically meaningful benefits. The metaanalysis suggests that psychopharmacotherapy can be effective in pediatric populations and represents safer alternatives to opioids in a population that is at high risk 
for tolerance, opioid hyperalgesia, deleterious hormonal changes, and opioid use disorder. ${ }^{38}$ Our findings may help create a pathway for designing a large randomized clinical trial to examine the role of individual or classspecific psychotropic medications to treat chronic pediatric pain.

Despite the auspicious results, our study has several limitations. First is the high degree of heterogeneity, which may include unknown variables that we were not able to control for. For instance, the definition of reduction in pain score and pain intensity scales were different among the included studies. Study by Bahar et al 2008 showed a greater response compared to other studies and results were heavily weight could be because of this. Furthermore, the chemical and clinical differences in the medications evaluated limit the conclusions that can be drawn regarding any single medication or class of medication, which may mask subtle inter-class differences. Also, the number of total number of studies were small to draw meaningful conclusions, and none contained over 100 patients per group, yet all were positive. This raises the possibility of some unknown source of bias, such as insufficient blinding. In addition, drug doses, duration of treatment, and follow-up intervals were different in the included studies, which limits generalizability. Importantly, it is possible that patient mood shifted at follow-up because of anti-depressants or anti-anxiety medications, which could have impacted pain ratings because of subjective improvement in their depression and/or anxiety. Lastly, because of the limited number of data points available from the included studies, analysis of other functional aspects of pain was not possible.

\section{Conclusions}

Despite its limitations, our study demonstrates the promising role of psychotropic medications in the treatment of chronic pediatric pain. These findings may pave the way for future randomized controlled trials of individual or classes medications for management of chronic pain in the younger population, a flagrantly underrepresented cohort. Our auspicious results support the need for more robust clinical trials to further investigate these promising findings, as positive studies in adults do not always translate well to children.

\section{Funding}

There is no funding to report.

\section{Disclosure}

Dr.Cohen, has received grants and personal fees from Scilex, grants from Avanos, personal fees from SPR Therapeutics, personal fees from Persica, Scintilla in the past 2 years none related to this manuscript. There is no conflict of interest for any of the authors.

\section{References}

1. Goodman JE, McGrath PJ. The epidemiology of pain in children and adolescents. A review. Pain. 1991;46(3):247-264. doi:10.1016/03043959(91)90108-A

2. Stanford EA, Chambers CT, Biesanz JC, Chen E. The frequency, trajectories and predictors of adolescent recurrent pain. A population-based approach. Pain. 2008;138(1):11-21. doi:10.1016/j. pain.2007.10.032

3. Friedrichsdorf SJ, Postier A, Eull D, et al. Pain outcomes in a US children's hospital. A prospective cross-sectional survey. Hosp Pediatr. 2015;5(1):18-26. doi:10.1542/hpeds.2014-0084

4. Perquin CW, Hazebroek-Kampscheur AAJM, Hunfeld JAM, et al. Pain in children and adolescents: a common experience. Pain. 2000;87(1):51-58. doi:10.1016/S0304-3959(00)00269-4

5. Palermo TM. Impact of recurrent and chronic pain on child and family daily functioning. A critical review of the literature. $J$ Dev Behav Pediatr. 2000;21(1):58-69. doi:10.1097/00004703-200002 000-00011

6. Roth-Isigkeit A, Thyen U, Raspe HH, Stoven H, Schmucker P. Reports of pain among German children and adolescents. An Epidemiological Study. Acta Paediatrica. 2004;93(2):258-263. doi:10.1111/j.1651-2227.2004.tb00717.x

7. Palermo TM, Kiska R. Subjective sleep disturbances in adolescents with chronic pain. Relationship to daily functioning and quality of life. J Pain. 2005;6(3):201-207. doi:10.1016/j.jpain.2004.12.005

8. Merlijn VP, Hunfeld JA, van der Wouden JC, HazebroekKampschreur AA, Koes BW, Passchier J. Psychosocial factors associated with chronic pain in adolescents. Pain. 2003;101(1):33-43. doi:10.1016/S0304-3959(02)00289-0

9. Gauntlett-Gilbert J, Eccleston C. Disability in adolescents with chronic pain. Patterns and predictors across different domains of functioning. Pain. 2007;131(1):132-141. doi:10.1016/j.pain.2006. 12.021

10. Kashikar-Zuck S, Goldschneider KR, Powers SW, Vaught MH, Hershey AD. Depression and functional disability in chronic pediatric pain. Clin J Pain. 2001;17(4):341-349. doi:10.1097/00002508200112000-00009

11. Jordan AL, Eccleston C, Osborn M. Being a parent of the adolescent with complex chronic pain: an interpretative phenomenological analysis. Eur J Pain. 2007;11(1):49-56. doi:10.1016/j.ejpain.2005. 12.012

12. Eccleston C, Crombez G, Scotford A, Clinch J, Connell H. Adolescent chronic pain. Patterns and predictors of emotional distress in adolescents with chronic pain and their parents. Pain. 2004;108 (3):221-229. doi:10.1016/j.pain.2003.11.008

13. Sleed M, Eccleston C, Beecham J, Knapp M, Jordan A. The economic impact of chronic pain in adolescence: methodological considerations and a Preliminary Costs-of-Illness Study. Pain. 2005;119 (1-3):183. doi:10.1016/j.pain.2005.09.028

14. Procyshyn RM, Bezchlibnyk-Butler KZ, Jeffries JJ, editors. Clinical Handbook of Psychotropic Drugs. Hogrefe Verlag; 2019.

15. Bahar RJ, Collins BS, Steinmetz B, Ament ME. Double-blind placebo-controlled trial of amitriptyline for the treatment of irritable bowel syndrome in adolescents. J Pediatr. 2008;152(5):685-689. doi:10.1016/j.jpeds.2007.10.012 
16. Roohafza H, Pourmoghaddas Z, Saneian H, Gholamrezaei A. Citalopram for pediatric functional abdominal pain. A randomized, placebo-controlled trial. $J$ Neurogastroenterol Motil. 2014;26 (11):1642-1650. doi:10.1111/nmo.12444

17. Badihian N, Yaghini O, Badihian S, Shahsanai A, Saneian H. Comparison of the efficacy of buspirone and placebo in childhood functional abdominal pain. a randomized clinical trial (2351). 2020.

18. Upadhyaya HP, Arnold LM, Alaka K, Qiao M, Williams D, Mehta R. Efficacy and safety of duloxetine versus placebo in adolescents with juvenile fibromyalgia. Results from a randomized controlled trial. Pediatr Rheumatol Online J. 2019;17(1):27. doi:10.1186/s12969019-0325-6

19. Saps M, Youssef N, Miranda A, et al. Multicenter, randomized, placebo-controlled trial of amitriptyline in children with functional gastrointestinal disorders. Gastroenterology. 2009;137(4):1261-1269. doi:10.1053/j.gastro.2009.06.060

20. Hjermstad MJ, Fayers PM, Haugen DF, et al. Studies comparing numerical rating scales, verbal rating scales, and visual analogue scales for assessment of pain intensity in adults: a systematic literature review. J Pain Symptom Manage. 2011;41(6):1073-1093. doi:10.1016/j.jpainsymman.2010.08.016

21. Cohen J. Statistical Power Analysis for the Behavioral Sciences. Hillsdale, NJ: Lawrence Erlbaum Associates; 1988.

22. Higgins JP, Altman DG, Gotzsche PC, et al. The Cochrane Collaboration's tool for assessing risk of bias in randomised trials. BMJ. 2011;343(oct18 2):d5928. doi:10.1136/bmj.d5928

23. Metafor: meta-analysis package for $\mathrm{R}$ [computer program]. Version 1.3-0. Netherlands: Viechtbauer W; 2010.

24. Schwarzer G, Schwarzer MG. Package 'meta'. The R foundation for statistical computing. 2012.

25. R: a language and environment for statistical computing [computer program]. Vienna, Austria: R Development Core Team; 2010.

26. Kosek E, Cohen M, Baron R, et al. Do we need a third mechanistic descriptor for chronic pain states? Pain. 2016;157(7):1382-1386. doi:10.1097/j.pain.0000000000000507

27. Brown S, Johnston B, Amaria K, et al. A randomized controlled trial of amitriptyline versus gabapentin for complex regional pain syndrome type I and neuropathic pain in children. Scand J Pain. 2016;13 (1):156-163. doi:10.1016/j.sjpain.2016.05.039

28. Salerno SM, Browning R, Jackson JL. The effect of antidepressant treatment on chronic back pain: a meta-analysis. Arch Gen Intern Med. 2002;162(1):19-24. doi:10.1001/archinte.162.1.19
29. Perrot S, Javier RM, Marty M, Le Jeunne C, Laroche F; CEDR (Cercle d'Etude de la Douleur en Rhumatologie France), French Rheumatological Society, Pain Study Section. Is there any evidence to support the use of anti-depressants in painful rheumatological conditions? Systematic review of pharmacological and clinical studies. Rheumatology (Oxford). 2008;47(8):1117-1123. doi:10.10 93/rheumatology/ken 110

30. Finnerup NB, Attal N, Haroutounian S, et al. Pharmacotherapy for neuropathic pain in adults. A systematic review and meta-analysis. Lancet Neurol. 2015;14(2):162-173. doi:10.1016/S1474-4422(14) 70251-0

31. Lyubashina OA, Busygina II, Panteleev SS, Nozdrachev AD. Antinociceptive effect of the agonist of 5-HT1A receptors buspirone in the model of abdominal pain in dogs. In: Doklady Biological Sciences. Vol. 473. Pleiades Publishing; 2017:46-49.

32. Panteleev SS, Sivachenko IB, Lyubashina OA. The central effects of buspirone on abdominal pain in rats. Neurogastroenterol Motil. 2018;30(11):e13431. doi:10.1111/nmo.13431

33. Jackson JL, Mancuso JM, Nickoloff S, Bernstein R, Kay C. Tricyclic and tetracyclic antidepressants for the prevention of frequent episodic or chronic tension-type headache in adults. A systematic review and meta-analysis. J Gen Intern Med. 2017;32(12):1351-1358. doi:10.1007/s11606-017-4121-z

34. Campo JV, Perel J, Lucas A, et al. Citalopram treatment of pediatric recurrent abdominal pain and comorbid internalizing disorders: an Exploratory Study. J Am Acad Child Adolesc Psychiatry. 2004;43 (10):1234-1242. doi:10.1097/01.chi.0000136563.31709.b0]

35. Walitt B, Urrútia G, Nishishinya MB, Cantrell SE, Häuser W. Selective serotonin reuptake inhibitors for fibromyalgia syndrome. Cochrane Database Syst Rev. 2015;2015(6):CD011735.

36. Patetsos E, Horjales-Araujo E. Treating chronic pain with SSRIs: what do we know? Pain Res Manag. 2016;2016:2020915. doi:10.1155/2016/2020915

37. Obata H. Analgesic mechanisms of antidepressants for neuropathic pain. Int J Mol Sci. 2017;18(11):2483. doi:10.3390/ijms18112483

38. Rosenberg JM, Bilka BM, Wilson SM, Spevak C. Opioid therapy for chronic pain: overview of the 2017 US department of veterans affairs and US department of defense clinical practice guideline. Pain Med. 2018;19(5):928-941. doi:10.1093/pm/pnx203
Journal of Pain Research

\section{Publish your work in this journal}

The Journal of Pain Research is an international, peer reviewed, open access, online journal that welcomes laboratory and clinical findings in the fields of pain research and the prevention and management of pain. Original research, reviews, symposium reports, hypothesis formation and commentaries are all considered for publication. The manuscript management system is completely online and includes a very quick and fair peer-review system, which is all easy to use. Visit http:// www.dovepress.com/testimonials.php to read real quotes from published authors. 